\title{
Relationship between Continuous Improvement and Internal Process Performance; the Role of Management Support
}

\author{
Vesna SESAR*, Anica HUNJET
}

\begin{abstract}
Many papers state the significant role of continuous improvement $(\mathrm{Cl})$ in achieving efficient and effective organization. Process performance can be enhanced with $\mathrm{Cl}$ practice since it can create knowledge about the process and make process change happen. The emphasis of the research was placed on adopting continuous improvement system in organizations which then supports a positive effect on internal process performance. In this relation, management support was analysed as a moderator variable that can strengthen the relationship between continuous improvement system and internal process performance. In order to examine the set hypothesis a research model was developed, and a survey was conducted on 113 Croatian companies that hold ISO 9001 certificate. To analyse this relation, regression analysis was performed. The results of the study showed that the link between continuous improvement system and internal processes performance is significant. Also, the results confirmed that management support strengthens the relationship between continuous improvement system and process performance.
\end{abstract}

Keywords: continuous improvement; internal process performance; kaizen; management; management support

\section{INTRODUCTION}

The continuous improvement $(C I)$ concept or kaizen was developed and spread by Masaaki Imai in the eighties in the last century [1]. As one of the strategic principles in total quality management (TQM), continuous improvement $(C I)$ has gained much attention in scientific literature and practice over time. Also, $C I$ has been widely practicing in manufacturing and service companies under Lean or Six Sigma methodologies. Theories like theory of constraints (TOC), resource-based view (RBV) and theory of organizational learning (OL) were dealing with its significance in organizations. $C I$ is defined as a continual endeavour to actively search and use new ways of improving work [2]. As stated from [2, 3] companies gain from continually improving processes.

Every day challenges in turbulent environment require agile responses. The benefits of $C I$ can be seen in adopting activities or specific behaviours of $C I$, in order to make fast reactions to these changing demands. If a company implements and manages right the $C I$ system, it can "enhance the organization's ability to make cohesive and quick process changes to improve performance" [2].

Recent literature perceives $C I$ as the dynamic capability representing "company's ability to integrate, build and reconfigure internal competencies and thus to address rapidly changing environments" [3]. Further, [4] argues that management commitment and culture opened to process orientation influences innovation performance. Also process improvement together with $C I$ is relevant to SME companies in overcoming companies limiting since they consist of "spectrum of activities, methods and approaches that seek to improve the effectiveness and efficiency of business processes over time and ensure the alignment of business processes with the competitive environment" [5]. Also, [6] noted that human factor contributes to sustainability of process improvements, therefore employees who have adopted specific $C I$ activities will bring to sustainability of $C I$ system and this effect will be seen in company's efficiency and effectiveness.

This research focuses on investigating the continuous improvement practice in Croatian companies that hold ISO
9001 certificate in terms of organisational effort that includes continuous improvement activities in company, and supports a positive effect of $C I$ system on internal process performance. In order to reduce variations in the process, that is to detect and eliminate them, companies can perceive $C I$ practice very useful. Primarily, because it is a simple concept that uses PDCA cycle (plan-do-check-act) which can represent a way to reduce those variations and make processes more effective and efficient [7].

Also, managers have to perceive $C I$ activities very important in their everyday tasks. Management support toward practicing the $C I$ in the company seems to be of an important role in sustaining the $C I$ initiative [8]. This support can contribute to employee empowerment [9] and motivation [10], which can consequently lead to better process performance or its lack can be a reason of process improvement failure [11].

To analyse the set relationship multiple regression analysis and correlation was performed.

\section{MODEL DEVELOPMENT AND HYPOTHESIS}

In this part of the paper the research model will be described (Fig. 1) with set hypothesis and literature review.

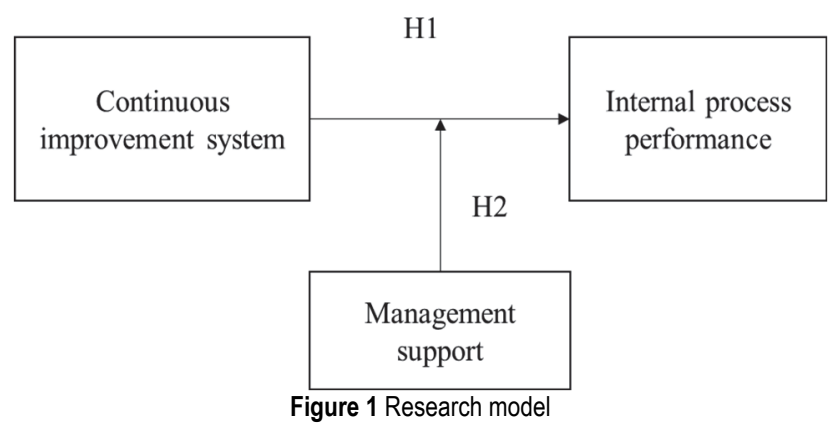

The research model consists of three constructs. The "Continuous improvement system" construct is an independent variable in the model and consists of seven variables (CI1, CI2, CI3, CI4, CI5, CI6 I CI7) which examine the application of $C I$ system in companies. First five variables $(C I 1-C I 5)$ measure whether companies have 
their strategy in line with $C I$ objectives which includes activities like monitoring, measuring and empowering $C I$ activities. Last two variables (CI6-CI7) measure whether companies have information system that supports $C I$ activities.

Variables are as follows: (1) developed business strategy in which the goals of improvement are clearly stated, $(C I 1),(2)$ whether the improvement objectives are expressed through key indicators (KPI's) whose achievement is regularly monitored, (CI2), (3) whether there is a measurement of improvements regularly (eg monthly, quarterly, annually) and how far the improvement goals have been achieved (eg. customers, finances, internal processes), (CI3), (4) whether the company regularly undertakes activities to ensure improvements, (CI4), (5) whether it provides funds (employees, time, money) to encourage improvements (eg customers, finances, internal process), (CI5). (6) whether the organization's information system allows easy monitoring of improvements, (CI6) (7) whether there are applications in the organization that monitor improvements, (CI7).

The "Internal process performance" construct presents the dependent variable in the model and consists of three variables: (1) Internal Process Efficiency, (2) Product/Service Innovation, and (3) Internal Process Innovation. The mean value of the construct "Internal process performance", (INT_PROC) was used to test the set hypotheses.

The "Management support" construct represents a moderator variable in the research model and consists of 4 variables: (1) Managers support the process of continuous improvement by allocating time, money, space and other resources, (TMS1), (2) Managers recognize in formal (not necessarily financial), the ways of employee's contribution to continuous improvement, (TMS2) (3) Managers are actively involved in the design and implementation of continuous improvement, (TMS3) (4) Managers support experiments by not punishing mistakes, instead they encourage learning from mistakes, (TMS4).

In order to build an efficient and effective organization, managers need to change the way they think and act. They have to adapt fast to everyday challenges and continuous improvement system could be a valuable concept to practice and gain advantages. Numerous studies have shown how successful application of continuous improvement contributes to the improvement of operational results, especially internal processes.

Research [12] showed that there is a positive relationship between continuous improvement and the success of internal processes. Also, [2] points out that by implementing continuous improvement, processes must be integrated, and this contributes to greater flexibility of the organization in changing its processes. Organizations that have integrated processes can adapt more quickly to new market requirements and situations. Because of this ability to adapt faster to change, an organization is more successful than the competition. Also, the research [4] found that practicing $C I$ activities in the company that adopted process approach leads to better time to market results in developing new products.

According to [13], the process perspective represents process performance and innovation in an organization, which is one of the four perspectives in measuring business performance within the well-known Balanced Scorecard framework. The other three business performance perspectives include the financial perspective, the customer perspective, and the employee learning and growth perspective. We argue that companies that implement and practice $C I$ lead to better internal process performance.

Following the literature review, the first hypothesis was set, H1: The continuous improvement system significantly influences internal process performance.

Authors [14] in their paper described a framework for improving the process of supply chain that includes personal participation of employees through the application of continuous improvement with special emphasis on improving organizational competence. Also, the need to involve management in the whole process of $C I$ implementation and application was emphasized by many prominent authors in the field of quality such as Juran, Feigenbaum, Deming, Shewart, Imai and others. Effective managers should represent an example to others through actions they take. Therefore, through numerous studies, management support has been highlighted as a factor that encourages the development and sustainability of a continuous improvement system. At the same time, the support of management, ie. its absence, is the most mentioned barrier that leads to deterioration of the same system [15-17]. Consequently, if the management's attitude is not in line with the behaviours related to continuous improvement activities, which they also expect from their employees, then it is unlikely that the employee will adopt and apply the expected behaviours and contribute to improving the system. We argue that companies which implement and practice $C I$ lead to better internal process performance, when there is a strong management support toward continuous improvement culture. Therefore, the aim of the research is to determine the importance of management support in strengthening the link between the continuous improvement system and internal processes success.

From the described problem, the second hypothesis was set, H2: Management support strengthens the relationship between continuous improvement system and internal processes performance.

\section{METHODOLOGY AND RESEARCH RESULTS}

In order to prove the set hypotheses, an empirical research was conducted in 2018 in the Republic of Croatia on organizations that hold ISO 9001 certificate, from different industries and size. For the purpose of the research, a questionnaire was developed based on previous research in the field of continuous improvement and business performance. For the constructs "Continuous improvement system" and "Management support" questions were asked based on the research of $[18,19]$. Also, the Likert scale from 1 to 5 was used, the respondents had to answer how much they agree with the set statement. Answer 1 represents "strongly disagree" and Answer 5 represents "strongly agree". For the construct "Internal process success" questions were asked based on [20]. The Likert scale from 1-5 was also used, where the respondents had to answer how much they agree with the statement in relation to the competition in the last three years. Answer 
1 represented "significantly behind the competition" and answer 5 represented "significantly better than the competition". The research base was provided by a private certification company in Croatia. The questionnaire was randomly sent to 400 addresses and sent to top managers who had the most experience in the field of continuous improvement. A total of 113 questionnaires was completed and the return rate was $28 \%$.

\subsection{Company Characteristics}

The research sample consists of $58 \%$ of small and medium size companies, $18 \%$ were micro companies and $24 \%$ big size companies (Tab. 1 ).

Table 1 Sample structure according to company size

\begin{tabular}{|c|c|c|c|c|}
\hline No. & Company size & Frequency & Percentage & Cumulative \\
\hline 1 & $\begin{array}{c}\text { Up to 10 } \\
\text { employees (micro) }\end{array}$ & 20 & 17,7 & 17,7 \\
\hline 2 & $\begin{array}{c}11-50 \text { employees } \\
\text { (small) }\end{array}$ & 29 & 25,7 & 43,4 \\
\hline 3 & $\begin{array}{c}51-250 \\
\text { employees } \\
\text { (medium) }\end{array}$ & 37 & 32,7 & 76,1 \\
\hline 4 & $\begin{array}{c}\text { more than 250 } \\
\text { employees (big) }\end{array}$ & 27 & 23,9 & 100 \\
\hline 5 & Total & 113 & 100 & \\
\hline
\end{tabular}

Regarding the industry, the largest percentage of surveyed companies are in the production sector $(53 \%)$. The rest of the companies are in the service sector $(38 \%)$ and $9 \%$ is in retail and wholesale (Tab. 2).

\begin{tabular}{|c|c|c|c|c|}
\hline \multicolumn{7}{|c|}{ Table 2 Sample structure by industry } \\
\hline No. & Industry & Frequency & Percent & Cumulative \\
\hline 1 & Production & 60 & 53,10 & 53,10 \\
\hline 2 & $\begin{array}{c}\text { Retail and } \\
\text { wholesale }\end{array}$ & 10 & 8,85 & 61,95 \\
\hline 3 & Services & 43 & 38,05 & 100,00 \\
\hline 4 & Total & 113 & 100.00 & \\
\hline
\end{tabular}

Regarding the ownership structure, most of the companies are domestically owned (81\%) and $19 \%$ are foreign-owned (Tab. 3).

Table 3 Sample structure by ownership

\begin{tabular}{|c|c|c|c|c|}
\hline No. & Ownership & Frequency & Percentage & Cumulative \\
\hline 1 & $\begin{array}{c}\text { Domestic } \\
\text { ownership }\end{array}$ & 92 & 81,4 & 81,4 \\
\hline 2 & $\begin{array}{c}\text { Foreign } \\
\text { ownership }\end{array}$ & 21 & 18,6 & 100 \\
\hline 3 & Total & 113 & 100 & \\
\hline
\end{tabular}

\subsection{Research Results}

In order to confirm the set hypotheses, a regression analysis was performed. For testing the reliability of scale a Cronbach's alpha was calculated for each construct individually. According to the general rule of a thumb it should be above 0,7 . Results show that all three constructs have a good internal consistency since values are above 0,8 (CI system construct; 0,913, management support construct; 0,895 and internal process construct; 0,880 ).

The analysis of the results showed that there is a significant link between continuous improvement system and internal processes performance. Also, management support has a moderating effect on the analysed relation.

Tab. 4 represents sample characteristics $(n=113)$, mean values and standard deviation. It can be seen that the highest mean value has variable CI3, (Is there a measurement of improvements regularly (eg monthly, quarterly, annually) and how far the improvement goals have been achieved (eg customers, finances, internal processes). Also, TMS3 (Managers are actively involved in the design and implementation of continuous improvement), and TMS4 (Managers support experiments by not punishing mistakes, instead they encourage learning from mistakes), have the highest mean values.

Table 4 Descriptive statistic

\begin{tabular}{|c|c|c|c|}
\hline \multicolumn{4}{|c|}{ Descriptive statistics } \\
\hline Variable name & Mean & Standard deviation & $N$ \\
\hline$I N T \_P R O C$ & 3,5664 & 0,86360 & 113 \\
\hline$C I 1$ & 4,04 & 0,935 & 113 \\
\hline$C I 2$ & 3,96 & 1,093 & 113 \\
\hline$C I 3$ & 4,15 & 1,011 & 113 \\
\hline$C I 4$ & 3,98 & 0,926 & 113 \\
\hline$C I 5$ & 3,91 & 0,950 & 113 \\
\hline$C I 6$ & 3,58 & 1,033 & 113 \\
\hline$C I 7$ & 2,90 & 1,224 & 113 \\
\hline$T M S 1$ & 3,78 & 0,923 & 113 \\
\hline$T M S 2$ & 3,73 & 0,945 & 113 \\
\hline$T M S 3$ & 3,84 & 0,912 & 113 \\
\hline$T M S 4$ & 3,84 & 0,931 & 113 \\
\hline
\end{tabular}

Hypothesis 1:

Tab. 5 shows the representativeness of the model for testing the hypothesis H1. That is, the relationship between the dependent variable (the mean value of the construct internal process performance, INT_PROC) and the independent variable, (variables of continuous improvement system, CI1,CI2, CI3, CI4, CI5, CI6 and $C I 7)$. According to the model, $31 \%$ of the variance of the dependent variable (INT_PROC) is explained by the variables of continuous improvement system; $C I 1, C I 2$, CI3, CI4, CI5, CI6 and CI7.

Table 5 Model summary

\begin{tabular}{|c|c|c|c|c|}
\hline \multicolumn{5}{|c|}{ Model Summary } \\
\hline Model & $R$ & $R$ Square & $\begin{array}{c}\text { Adjusted } R \\
\text { Square }\end{array}$ & $\begin{array}{c}\text { Std. Error of the } \\
\text { Estimate }\end{array}$ \\
\hline 1 & $0,560^{\text {a }}$ & 0,314 & 0,268 & 0,73872 \\
\hline \multicolumn{4}{|l}{ a. Predictors: (Constant), CI7,CI3,CI6,CI5,CI2,CI4,CI1 } \\
\hline
\end{tabular}

The results of the Anova test (Tab. 6) show that the significance of the test is less than $0.01(\mathrm{sig}=0.000)$ which means that zero hypothesis is rejected and the alternative hypothesis is accepted, representing that at least one independent variable in the model has a positive effect on the dependent variable internal processes performance (INT_PROC).

Table 6 ANOVA ANOVA $^{\mathrm{a}}$

\begin{tabular}{|c|c|c|c|c|c|c|}
\hline \multicolumn{7}{|c|}{ ANOVA $^{\mathrm{a}}$} \\
\hline \multicolumn{2}{|r|}{ Model } & Sum of Squares & $d f$ & Mean Square & $F$ & Sig. \\
\hline \multirow{3}{*}{1} & Regression & 26,231 & 7 & 3,747 & 6,867 & $0,000^{\mathrm{b*}}$ \\
\hline & Residual & 57,299 & 105 & 0,546 & & \\
\hline & Total & 83,530 & 112 & & & \\
\hline \multicolumn{7}{|c|}{ a. Dependent Variable: $I N T \_P R O C$} \\
\hline \multicolumn{7}{|c|}{ b. Predictors: (Constant), $\mathrm{CI} \overline{7}, \mathrm{CI} 3, \mathrm{CI} 6, \mathrm{CI} 5, \mathrm{CI} 2, \mathrm{CI} 4, \mathrm{CI} 1$} \\
\hline
\end{tabular}


Also, Fig. 2 shows that the results are around zero. Therefore, there is no deviation greater than 3.3 or -3.3 , and the homogeneity of variance is satisfied.

Hypothesis 2:

Tab. 7 represents a summary of the two models. It is evident that in Model 2, management support significantly contributes to the explanation of the variance of the dependent variable, internal processes performance. Model 1 explains $31 \%$, and model $2,43 \%$ of the variance of the dependent variable INT_PROC. By adding the variables "Management support" (variables TMS1 to TMS4) to the model, the explanation of variance increases by $11.4 \%$ (R Square Change) and this is statistically significant at $1 \%$ level, Sig $=001$. Regression equation of the Model 1 is $I N T \_P R O C=1,413+0,277 \times C I 5+0,210 \times C I 6$, regression equation of Model 2 is INT_PROC $=0,968+$ $0,199 \times C I 6+0,338 \times T M S 2+0,276 \times T M S 4$.

Table 7 Model summary

Model Summary

\begin{tabular}{|c|c|c|c|c|c|c|c|c|c|}
\hline \multicolumn{10}{|c|}{ Model Summary } \\
\hline \multirow[t]{2}{*}{ Model } & \multirow[t]{2}{*}{$R$} & \multirow[t]{2}{*}{$R$ Square } & \multirow{2}{*}{$\begin{array}{l}\text { Adjusted } R \\
\text { cSquare }\end{array}$} & \multirow{2}{*}{$\begin{array}{l}\text { Std. Error of the } \\
\text { Estimate }\end{array}$} & \multicolumn{5}{|c|}{ Change Statistics } \\
\hline & & & & & $\begin{array}{c}R \text { Square } \\
\text { Change }\end{array}$ & $F$ Change & $d f 1$ & $d f 2$ & Sig. F Change \\
\hline 1 & $0,560^{\mathrm{a}}$ & 0,314 & 0,268 & 0,73872 & 0,314 & 6,867 & 7 & 105 & $0,000^{*}$ \\
\hline 2 & $0,655^{\mathrm{b}}$ & 0,428 & 0,366 & 0,68755 & 0,114 & 5,053 & 4 & 101 & $0,001 *$ \\
\hline \multicolumn{10}{|c|}{ a. Predictors: (Constant), $C I 7, C I 3, C I 6, C I 5, C I 2, C I 4, C I 1$} \\
\hline \multicolumn{10}{|c|}{ b. Predictors: (Constant), CI7, CI3, CI6, CI5, CI2, CI4, CI1, TMS1, TMS2, TMS4, TMS3 } \\
\hline \multicolumn{10}{|c|}{ c. Dependent Variable: $I N T \_P R O C$} \\
\hline
\end{tabular}

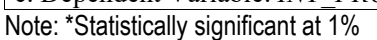

The results of the Anova test (Tab. 8) represent two Models. Model 1 and Model 2 are statistically significant at $1 \%$ probability. Anova shows that by adding the variables "Management Support" in Model 2, the significance of the test is less than $0.01(\mathrm{sig}=0.000)$, which means that at least one of these variables significantly strengthens the link between continuous improvement system and internal processes performance.

\begin{tabular}{|c|c|c|c|c|c|c|}
\hline \multicolumn{7}{|c|}{ ANOVA $^{\mathrm{a}}$} \\
\hline & & Sum of Squares & $d f$ & Mean Square & $F$ & Sig. \\
\hline \multirow{3}{*}{1} & Regression & 26,231 & 7 & 3,747 & 6,867 & $0,000^{b}$ \\
\hline & Residual & 57,299 & 105 & 0,546 & & \\
\hline & Total & 83,530 & 112 & & & \\
\hline \multirow{3}{*}{2} & Regression & 35,785 & 11 & 3,253 & 6,882 & $0,000^{\mathrm{c}}$ \\
\hline & Residual & 47,745 & 101 & 0,473 & & \\
\hline & Total & 83,530 & 112 & & & \\
\hline \multicolumn{7}{|c|}{ Dependent Variable: $I N T \_P R O C$} \\
\hline \multicolumn{7}{|c|}{ b. Predictors: (Constant), $C I 7, C I 3, C I 6, C I 5, C I 2, C I 4, C I 1$} \\
\hline \multicolumn{7}{|c|}{ c. Predictors: (Constant), $C I 7, C I 3, C I 6, C I 5, C I 2, C I 4, C I 1, T M S 1, T M S 2, T M S 4, T M S 3$} \\
\hline
\end{tabular}

Note: * Statistically significant at $1 \%$

Table 9 Coefficients of the Model 1 and Model 2

\begin{tabular}{|c|c|c|c|c|c|c|c|c|}
\hline \multicolumn{9}{|c|}{ Coefficients $^{\mathrm{a}}$} \\
\hline & \multirow[t]{2}{*}{ Model } & \multicolumn{2}{|c|}{$\begin{array}{l}\text { Unstandardized } \\
\text { Coefficients }\end{array}$} & \multirow{2}{*}{$\begin{array}{c}\text { Standardized Coefficients } \\
\text { Beta } \\
\end{array}$} & \multirow[t]{2}{*}{$t$} & \multirow[t]{2}{*}{ Sig. } & \multicolumn{2}{|c|}{$95,0 \%$ Confidence Interval for B } \\
\hline & & $\mathrm{B}$ & Std. Error & & & & Lower Bound & Upper Bound \\
\hline \multirow{5}{*}{1} & (Constant) & 1,413 & 0,344 & & 4,108 & $0,000 *$ & 0,731 & 2,095 \\
\hline & $C I 1$ & 0,190 & 0,152 & 0,206 & 1,248 & 0,215 & $-0,112$ & 0,493 \\
\hline & $C I 2$ & 0,035 & 0,116 & 0,045 & 0,304 & 0,762 & $-0,195$ & 0,265 \\
\hline & $C I 3$ & $-0,111$ & 0,142 & $-0,130$ & $-0,783$ & 0,435 & $-0,393$ & 0,171 \\
\hline & $C I 4$ & $-0,014$ & 0,140 & $-0,015$ & $-0,100$ & 0,921 & $-0,292$ & 0,264 \\
\hline & $C 15$ & 0,277 & 0,122 & 0,305 & 2,273 & $0,025 * *$ & 0,035 & 0,519 \\
\hline & CI6 & 0,210 & 0,095 & 0,251 & 2,205 & $0,030 * *$ & 0,021 & 0,399 \\
\hline & $C I 7$ & $-0,026$ & 0,077 & $-0,036$ & $-0,331$ & 0,741 & $-0,179$ & 0,128 \\
\hline \multirow{12}{*}{2} & (Constant) & 0,968 & 0,352 & & 2,754 & $0,007 * * *$ & 0,271 & 1,665 \\
\hline & $C I 1$ & 0,113 & 0,145 & 0,123 & 0,782 & 0,436 & $-0,174$ & 0,401 \\
\hline & $C I 2$ & 0,064 & 0,109 & 0,081 & 0,589 & 0,557 & $-0,152$ & 0,280 \\
\hline & $C 13$ & $-0,185$ & 0,135 & $-0,216$ & $-1,366$ & 0,175 & $-0,453$ & 0,084 \\
\hline & $C I 4$ & 0,033 & 0,133 & 0,035 & 0,247 & 0,806 & $-0,231$ & 0,297 \\
\hline & $C 15$ & 0,090 & 0,134 & 0,099 & 0,672 & 0,503 & $-0,176$ & 0,356 \\
\hline & CI6 & 0,199 & 0,089 & 0,238 & 2,239 & $0,027 * *$ & 0,023 & 0,376 \\
\hline & $C I 7$ & $-0,130$ & 0,077 & $-0,185$ & $-1,700$ & $0,092 *$ & $-0,282$ & 0,022 \\
\hline & $T M S 1$ & $-0,095$ & 0,097 & $-0,102$ & $-0,985$ & 0,327 & $-0,287$ & 0,097 \\
\hline & $T M S 2$ & 0,338 & 0,122 & 0,370 & 2,783 & $0,006 * * *$ & 0,097 & 0,579 \\
\hline & TMS3 & $-0,034$ & 0,138 & $-0,036$ & $-0,247$ & 0,805 & $-0,309$ & 0,240 \\
\hline & TMS4 & 0,276 & 0,118 & 0,298 & 2,342 & $0,021 * *$ & 0,042 & 0,511 \\
\hline
\end{tabular}

Note: Statistically significant at ${ }^{* * *} 1 \%,{ }^{* *} 5 \%,{ }^{*} 10$

Tab. 9 represents the coefficients of Model 1 and Model 2. In Model 1 variables of continuous improvement system that influence internal process performance are:
CI5 (Our company provides funds (employees, time, money) to encourage improvements (eg. customers, finances, internal process), $($ sig $=0.025)$ and CI6 (Our 
organization's information system allows easy monitoring of improvements $),(\mathrm{sig}=0.030)$ contribute significantly to the link between continuous improvement and internal processes.

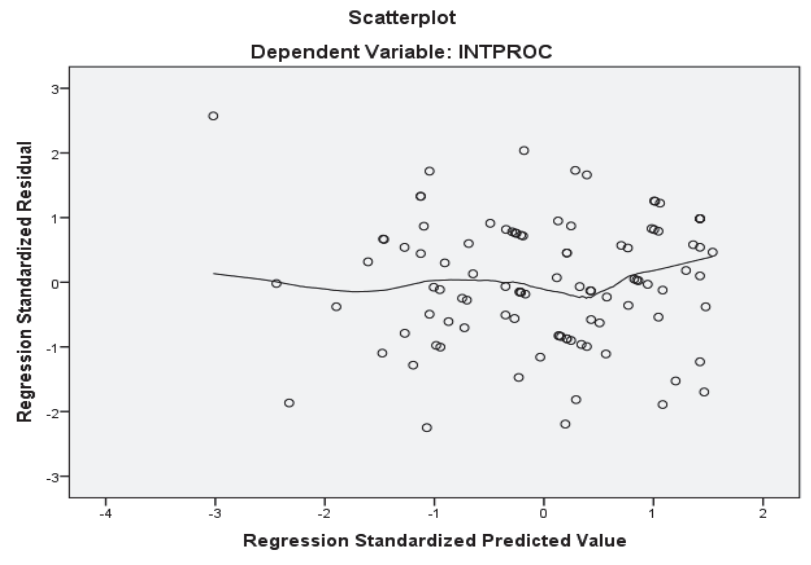

Figure 2 Scatter plot - Hypothesis H1

According to the results of the analysis, hypothesis $\mathrm{H} 1$ : The continuous improvement system significantly influences internal process performance is accepted.

From Model 2 it can be seen that management support variables strengthen the relationship between CI system and internal process performance. Two variables are significant and positively influence the relation. Variable, TMS2 (Managers recognize in formal (not necessarily financial), ways of employee's contribution to continuous improvement), $(\operatorname{sig}=0.006)$ and TMS4 (Managers support experiments by not punishing mistakes, instead they encourage learning from mistakes), ( $\mathrm{sig}=0.021)$.

Therefore, the second hypothesis H2: Managemen support strengthens the relationship between continuous improvement system and internal processes performance, is accepted.

\section{CONCLUSION}

The paper presents the results of a research aimed at examining the application of $C I$ system in companies and whether there is a significant relationship between continuous improvement system application and its impact on internal processes performance. Furthermore, management support was analysed as moderator variable that can strengthen this relation. The research was conducted on a sample of 400 organizations that hold an ISO 9001 certificate. The survey method was used and the questionnaire was sent by e-mail. The rate of return is $28 \%$ (113 questionnaires).

Conducted data and regression analysis confirmed the significant impact of continuous improvement system on internal process performance. Regression analysis showed that significant impact in this relation is seen in encouraging improvements through providing funds (employees, time, money) as well as having developed information system for easier improvement monitoring. Also, the results imply, based on the high mean values, that companies with $C I$ system have strategies that include improvement goals. However, low mean values (variables CI6 and CI7) imply that information system in surveyed companies is not in line with monitoring the $C I$ improvements. This finding could be interesting for future research in analysing the role of information system in measuring and sustaining the $C I$ activities in companies.

Also, the important role of management support was confirmed. Model 1 explains $31 \%$ of the variance of the dependent variable INT PROC, and Model 2 where moderator variable management support was added, explains $43 \%$ of the variance of the dependent variable INT_PROC. Research results have practical implications for managers. Results show that managers must be aware of their significant role in the process of implementing, practicing and sustaining the $C I$ system in the organization by recognizing employee's contribution to $C I$ activities as well as by encouraging learning from mistakes. Previous researches have shown that the absence of management support consequently affects the success of internal processes performance, as well as the motivation of employees in continuous improvement activities. Therefore, managers who implement and practice $C I$ in the organization, and provide a positive example to their employees, contribute to a better organizational climate and better results. Such an approach allows the organization greater agility in the market, which is indispensable in today's environment.

Limitation of the study can be perceived in analysing only companies that hold ISO 9001 certificate. In future it would be interesting to analyse the impact of $C I$ in companies with no certification and make comparisons.

Also, the questionnaire was sent to top managers which can be limiting since top managements usually want to present the current state in their company positively. Implication for future research would be in including the view of other management levels as well as employees.

For a deeper understanding of the $C I$ system it would be useful to address how companies implement $C I$ system, which techniques and behaviours they use and how they measure the results of $C I$ activities. Also, how they acknowledge employee's contribution to $C I$ efforts.

Based on the research results and literature review, the application of a $C I$ system in the organization can represent a good management strategy to follow in increasing process performance. This path can excel company's sustainability.

\section{REFERENCES}

[1] Sanchez, L. \& Blanco, B. (2014). Three decades of continuous improvement. Total Quality Management \& Business Excellence, 25(9-10), 986-1001. https://doi.org/10.1080/14783363.2013.856547

[2] Anand, G., Ward, P. T., Tatikonda, M. V., \& Schilling, D. A. (2009). Dynamic capabilities through continuous improvement infrastructure. Journal of operations management, 27(6), 444-461. https://doi.org/10.1016/j.jom.2009.02.002

[3] Teece, D. J. (2007). Explicating dynamic capabilities: the nature and microfoundations of (sustainable) enterprise performance. Strategic management journal, 28(13), 13191350. https://doi.org/10.1002/smj.640

[4] Kohlbacher, M. (2013). The impact of dynamic capabilities through continuous improvement on innovation: The role of business process orientation. Knowledge and Process Management, 20(2), 71-76. https://doi.org/10.1002/kpm.1405

[5] Matthews, R. L. \& Marzec, P. E. (2017). Continuous, quality and process improvement: disintegrating and reintegrating 
operational improvement? Total Quality Management \& Business Excellence, 28(3-4), 296-317. https://doi.org/10.1080/14783363.2015.1081812

[6] Bateman, N. (2005). Sustainability: the elusive element of process improvement. International journal of operations \& production management., 25(3), 261-276. https://doi.org/10.1108/01443570510581862

[7] Gisi, P. J. (2018). Sustaining a culture of process control and continuous improvement: The roadmap for efficiency and operational excellence. Taylor \& Francis. https://doi.org/10.4324/9781315099361

[8] Butler, M., Szwejczewski, M., \& Sweeney, M. (2018). A model of continuous improvement programme management. Production Planning \& Control, 29(5), 386-402. https://doi.org/10.1080/09537287.2018.1433887

[9] Hirzel, A. K., Leyer, M., \& Moormann, J. (2017). The role of employee empowerment in the implementation of continuous improvement. International Journal of Operations \& Production Management, 37(10), 1563-1579. https://doi.org/10.1108/IJOPM-12-2015-0780

[10] Lodgaard, E., Ingvaldsen, J. A., Aschehoug, S., \& Gamme, I. (2016). Barriers to continuous improvement: perceptions of top managers, middle managers and workers. Procedia CIRP, 41, 1119-1124. https://doi.org/10.1016/j.procir.2016.01.012

[11] Antony, J. \& Gupta, S. (2019). Top ten reasons for process improvement project failures. International Journal of Lean Six Sigma, 10(1), 367-374. https://doi.org/10.1108/IJLSS-11-2017-0130

[12] García, J. L., Maldonado, A. A., Alvarado, A., \& Rivera, D. G. (2014). Human critical success factors for kaizen and its impacts in industrial performance. The International Journal of Advanced Manufacturing Technology, 70(9-12), 21872198. https://doi.org/10.1007/s00170-013-5445-4

[13] Kaplan, R. S. \& Norton, D. P. (2001). Transforming the balanced scorecard from performance measurement to strategic management: Part II. Accounting horizons, 15(2), 147-160. https://doi.org/10.2308/acch.2001.15.2.147

[14] Prado-Prado, J. C., García-Arca, J., \& Fernández-González, A. J. (2020). People as the key factor in competitiveness: a framework for success in supply chain management. Total Quality Management \& Business Excellence, 31(3-4), 297311. https://doi.org/10.1080/14783363.2018.1427499

[15] Parumasur, S. B. (2013). The importance of teamwork, continuous top management support and training in bringing about TQM. Journal of Economics and Behavioral Studies, 5(9), 639-651. https://doi.org/10.22610/jebs.v5i9.437

[16] McLean, R. \& Antony, J. (2014). Why continuous improvement initiatives fail in manufacturing environments? A systematic review of the evidence. International Journal of Productivity and Performance Management., 63(3), 370376. https://doi.org/10.1108//JPPM-07-2013-0124

[17] Jurburg, D., Viles, E., Tanco, M., \& Mateo, R. (2018). Continuous improvement leaders, followers and laggards: understanding system sustainability. Total Quality Management \& Business Excellence, 29(7-8), 817-833. https://doi.org/10.1080/14783363.2016.1240610

[18] Jurburg, D., Viles, E., Jaca, C., \&Tanco, M. (2015). Why are companies still struggling to reach higher continuous improvement maturity levels? Empirical evidence from high performance companies. The TQM Journal., 27(3), 316-327. https://doi.org/10.1108/TQM-11-2013-0123

[19] Bessant, J., Caffyn, S., \& Gallagher, M. (2001). An evolutionary model of continuous improvement behaviour. Technovation, 21(2), 67-77. https://doi.org/10.1016/S0166-4972(00)00023-7

[20] Kim, J. \& Rhee, J. (2012). An empirical study on the impact of critical success factors on the balanced scorecard performance in Korean green supply chain management enterprises. International Journal of Production Research, 50(9), 2465-2483.

https://doi.org/10.1080/00207543.2011.581009

\section{Coontact information:}

Vesna SESAR, PhD

(Corresponding author)

University North,

University center Varaždin

Jurja Križanića 31b,

42000 Varaždin, Croatia

E-mail: vesna.sesar@unin.hr

Anica HUNJET, prof. dr.sc.

University North,

University center Varaždin,

Jurja Križanića $31 b$,

42000 Varaždin

E-mail: anica.hunjet@unin.hr 